\title{
Revisão conceitual, padrões microestruturais e proposta nomenclatória para os pêlos-guarda de mamíferos brasileiros
}

\author{
Juliana Quadros ${ }^{1} \&$ Emygdio L. de A. Monteiro-Filho ${ }^{2}$ \\ ${ }^{1}$ Rua Piraí do Sul 51. Vila São José, Augusta. 81290-170 Curitiba, Paraná, Brasil. \\ 2 Departamento de Zoologia, Setor de Ciências Biológicas, Universidade Federal do Paraná. Caixa Postal 19020, \\ 81531-980 Curitiba, Paraná, Brasil.
}

\begin{abstract}
Review of concepts, microstructural patterns and nomenclature proposal to the guard-hairs of Brazilian mammals. As an introduction this study presents a literature review on the concepts applied in tricology emphasizing studies on hair microstructure. Tricologists described and named several microstructural patterns of cuticle and medulla, but the nomenclature is too diverse and most works lack drawings and photographs to illustrate described patterns. Additionaly, the translation of terms commonly found in the bibliography, most in English and French, would lead to meaningless denominations in Portuguese. In this sense, the present work aimed to describe the microstructural patterns of cuticle and medulla found in 64 Brazilian mammal species and to propose a nomenclature in Portuguese to these patterns. Fifteen cuticular patterns were described and named on the basis of six characters: scale imbrication, form, dimensions and orientation; scale margins ornamentation and continuity. Considering the medulla, 17 medullar patterns were described and named on the basis of six characters: medulla presence, continuity, number of cell rows, cell disposition, cell shape and the ornamentation of medullar margins. The results obtained and the descriptions and drawings of cuticular and medullar patterns available in the literature were discussed.

KEY WORDS. Mastozoology; microstructure; Neotropical; techniques; tricology.
\end{abstract}

RESUMO. Como introdução este trabalho apresenta uma revisão bibliográfica de conceitos aplicados em tricologia com ênfase na microestrutura dos pêlos. Tricologistas descreveram e nomearam vários padrões microestruturais da cutícula e medula, mas a nomenclatura é bastante diversa e a maioria dos trabalhos não apresenta desenhos ou fotografias para ilustrar os padrões descritos. Adicionalmente, a tradução dos termos comumente encontrados na bibliografia, a maioria em inglês e francês, levaria a denominações sem sentido em português. Nesse sentido, o presente trabalho tem por objetivos descrever os padrões microestruturais da cutícula e medula de 64 espécies de mamíferos brasileiros e propor uma nomenclatura em português para estes padrões. Quinze padrões cuticulares foram descritos e nomeados com base em seis caracteres: imbricamento, forma, dimensão e orientação das escamas; ornamentação e continuidade das bordas das escamas. Considerando a medula, 17 padrões foram descritos e nomeados com base em seis caracteres: presença, continuidade, número de fileiras de células na medula; disposição e forma destas células e ornamentação da margem da medula. Os resultados obtidos e as descrições e desenhos dos padrões cuticulares e medulares disponíveis na literatura foram discutidos.

PALAVRAS CHAVE. Mastozoologia; microestrutura; Neotropical; técnicas; tricologia.

Os pêlos são anexos epidérmicos queratinizados exclusivos dos mamíferos. Apresentam as funções de termorregulação, dissimulação no ambiente e proteção mecânica (HERSHKOVITZ 1977, Pough et al. 1999).

Dennler (1939) estudando a estrutura da pelagem dos mamíferos sulamericanos, caracterizou três tipos de configurações: monozonária (apenas um tipo de pêlo), bizonária (dois tipos de pêlos formando duas zonas) e trizonária (três tipos de pêlos delimitando três zonas distintas). Para Moojen (1952) a pelagem trizonária é formada por pêlos aristiformes (os mais desenvolvidos: guard hairs, leithaar, jarre, cerda), pêlos setiformes (os mais numerosos: overhairs, grannenhaare, soies, pêlos setosos) e os pêlos viliformes (os menores: underfur, wolhaar, duvet, lanugem). Cada uma destas categorias pode ser adjetivada e subdividida, como por exemplo, pêlos aristiformes lanceolares e pêlos aristiformes aculeados. Como o número de tipos de pêlos e suas características morfológicas são variáveis de acordo com a espécie, idade do indivíduo, época da muda da pelagem e o autor (Moojen 1952, BRUnNer \& Coman 1974, Teerink 1991), neste trabalho é utilizada a nomen- 
clatura de tipos de pêlos proposta por TEerink (1991). Este autor sugere que os pêlos sejam divididos em duas grandes categorias: os pêlos-guarda ("overhairs") e os subpêlos ("underhairs"). Os subpêlos são mais numerosos, mais ondulados, mais curtos, apresentam constrições (MATHIAK 1938, DAY 1966) e na grande maioria dos casos são inúteis na identificação de amostras desconhecidas, pois são semelhantes entre espécies diferentes (TeErink 1991). Os pêlos-guarda, primários e secundários, apresentam ao longo de seu comprimento duas porções principais: a haste ("shaft") e o escudo ("shield"). A primeira é a porção que se segue ao bulbo do pêlo, é mais estreita e reta ou ondulada. O segundo é alargado e fica entre a haste e a extremidade distal do pêlo (Day 1966, Charvet \& Keller 1989, Teerink 1991).

Os pêlos são formados por três camadas concêntricas de células queratinizadas, sendo a cutícula, a mais externa; o córtex, a intermediária; e a medula, a mais interna (TEERINK 1991). Essas três camadas apresentam padrões morfológicos que, combinados entre si, conferem a uma determinada espécie características diagnósticas específicas, sendo, portanto, estruturas anatômicas de grande valia na identificação das espécies. São as características cuticulares na haste e medulares e corticais no escudo dos pêlos-guarda, primários e secundários, as mais úteis na identificação de amostras desconhecidas. QuADros \& Monteiro-Filho (1998b), estudando pêlos do gambá-de-orelhabranca, Didelphis albiventris Lund, 1840, afirmam que o padrão medular é particularmente útil, pois varia menos entre os tipos de pêlos do que o padrão cuticular.

A queratinização dos pêlos lhes confere grande resistência, possibilitando a comparação de pêlos com diferentes origens (espécimes taxidermizados, amostras fecais, egagrópilas, conteúdos gastrintestinais e carcaças) entre si, independentemente dos processos químicos (taxidermia e digestão) e mecânicos (mastigação e intemperismo) aos quais tenham sido submetidos (Quadros \& Monteiro-Filho 1998a). Os trabalhos de KeLler (1978) e TeERINK (1991) também corroboram o fato, mostrando que os pêlos são resistentes ao processo digestivo e que as alterações, porventura causadas, não comprometem a identificação.

No que se refere à comparação de pêlos provenientes de diferentes partes do corpo de uma mesma espécie, MathiaK (1938), Mayer (1952), Day (1966) e Riggott \& Wyatt (1980) mostraram que eles podem ser comparados entre si, sem prejuízos na identificação, excetuando-se os pêlos das extremidades como as orelhas, cabeça, pescoço, cauda e patas. De acordo com Keogh (1985), embora o material analisado por ela para elaboração da chave de identificação tenha sido do dorso dos espécimes, os resultados obtidos foram consistentes com pêlos do ventre e do flanco. Ainda nesse sentido, de acordo com observações pessoais dos autores (dados não publicados) os padrões cuticular e medular apresentam diferenças insignificantes entre pêlos de diferentes partes do corpo. Considerando diferenças morfológicas entre pêlos de machos e fêmeas, RIGGOTT \& WyatT (1980) encontraram variações somente nos pêlos da cabeça de ratos de laboratório, permanecendo as demais partes do corpo sem dimorfismo sexual. Tratando-se especialmente de pêlos de diferentes partes do corpo de espécies de marsupiais, o conhecimento que se tem ainda é incipiente, destacando-se o trabalho de Oliverina et al. (1992) que alertam para a existência de dimorfismo sexual na estrutura da pelagem da região escapular de Marmosops incanus (Lund, 1840). Entretanto, não foi averiguada a relação entre a diferença na estrutura da pelagem (tipos de pêlos) e suas características microscópicas (cutícula, medula e córtex dos pêlos).

O que determina a coloração que vemos macroscopicamente é a quantidade de melanina presente nos pêlos e o tipo (feomelanina e eumelanina), assim como a presença ou ausência de bolhas de ar na medula. O "Princípio do Metacromismo" proposto por Hershrovitz (1977) explica as múltiplas tonalidades encontradas na pelagem dos mamíferos sejam elas de natureza ontogenética, filogenética, geográfica, sazonal, sexual ou individual. Devido às múltiplas possibilidades de variação intraespecífica e sobreposição interespecífica (MAYER 1952, RiggotT \& WyATT 1980) a cor dos pêlos tem sua utilização limitada nas chaves de identificação. Entretanto, vários autores (MAYER 1952, Stains 1958, Hilton \& Kutscha 1978, Taylor 1985, Thompson et al. 1987, Oli 1993, Wallis 1993, Chakraborty et al. 1996, De et al. 1998) utilizam a coloração dos pêlos em parceria com o tamanho (diâmetro e comprimento) e com características micro estruturais da medula, córtex e cutícula.

Ao longo da história da tricologia, vários autores descreveram e nomearam padrões micro estruturais dos pêlos-guarda e propuseram guias de identificação. Dentre eles destaca-se o trabalho realizado na América do Norte por Hausman (1920), que forneceu pela primeira vez, caracteres diagnósticos para 166 espécies e elaborou um sistema de nomenclatura para oito padrões de cutícula e oito padrões de medula; LomUlLer (1924) na França trabalhou com 93 espécies de mamíferos e descreveu 42 padrões medulares e 11 cuticulares, vários já descritos por [Leon Augustus] Hausman (1920); Mathiak (1938) propôs uma terminologia própria para se referir a padrões micro estruturais de 42 espécies da América do Norte; Wildman (1954) e ApPelyard (1960) fizeram revisões extensas dos padrões micro estruturais e das técnicas que podem ser utilizadas na identificação de fibras animais comercializadas; BeNEDICT (1957) trabalhou exclusivamente com pêlos de quirópteros e produziu um guia de identificação com cerca de 14 padrões cuticulares e seis medulares para aproximadamente 150 gêneros do mundo e que não foi igualado para nenhum outro grupo de mamíferos; BRUNNER \& ComAn (1974) apresentaram 12 padrões cuticulares, nove medulares e algumas variações que permitiram a identificação de 75 espécies de mamíferos da Austrália; Perrin \& Campbell (1980), descreveram oito padrões de cutícula e fizeram chaves ilustradas para a identificação dos pêlos voltadas para a análise de fezes de carnívoros africanos; Keller (1980) descreveu alguns padrões medulares e cuticulares de pêlos-guarda de 11 famílias de mamíferos e propôs uma nomenclatura para esses

Revista Brasileira de Zoologia 23 (1): 279-292, março 2006 
padrões; KеоGH (1983) descreveu padrões micro estruturais para 32 espécies de bovídeos da África; Keogh (1985) trabalhou com 44 espécies de roedores, também descrevendo novos padrões de cutícula e sugerindo a respectiva nomenclatura e TeERINK (1991) realizou a mais recente revisão de técnicas e padrões descrita na literatura, apresentando chaves de identificação para 73 espécies de mamíferos do oeste europeu.

A despeito dos esforços dos tricólogos na descrição de padrões micro estruturais dos pêlos-guarda de mamíferos e na elaboração de chaves de identificação, muitas vezes os padrões são de difícil interpretação devido à falta de descrições mais detalhadas acompanhadas de ilustrações e à falta de uma nomenclatura padronizada para se referir aos caracteres em seus diversos estados.

Particularmente em relação ao estudo dos mamíferos com ocorrência no Brasil, há alguns trabalhos não publicados (resumos em congressos e dissertação de mestrado) e as raras informações publicadas foram apresentadas por CHEHÉBAR \& MARTíN (1989) para 12 espécies, Fernández \& Rossi (1998) para duas espécies e por VÁzquEz et al. (2000) para 16 espécies.

Nesse sentido, os objetivos do presente trabalho foram descrever os padrões morfológicos observados na microestrutura da cutícula e da medula dos pêlos-guarda de mamíferos encontrados no Brasil e propor uma classificação e nomenclatura, em português, para estes padrões.

\section{MATERIAL E MÉTODOS}

\section{Espécies estudadas}

As espécies abordadas nesse trabalho foram selecionadas de acordo com o interesse de identificação de predadores e presas por meio de seus pêlos-guarda encontrados em amostras fecais de carnívoros coletadas na Reserva Volta Velha (RVV), uma unidade de conservação privada com 586 ha, situada no Município de Itapoá, no extremo nordeste do Estado de Santa Catarina. De acordo com Quadros \& Cáceres (2001), 47 espécies de mamíferos têm ocorrência confirmada para a RVV. No presente trabalho, foram abordadas estas espécies e também outras 17 , que embora não tenham sido registradas na área até o momento, apresentam potencial de ocorrência (EMmons \& FEER 1997, Michel Miretzki com. pess.). Nesse sentido, foram analisadas amostras de pêlos coletadas de 646 indivíduos de 64 espécies de mamíferos pertencentes aos acervos científicos do Museu de História Natural Capão da Imbuia (MHNCI, Curitiba, PR), do Museu Nacional, Universidade Federal do Rio de Janeiro (MNRJ, Rio de Janeiro, RJ), do Museu de Zoologia, universidade de São Paulo (MZUSP, São Paulo, SP), do Museu de Zoologia, Universidade Estadual de Campinas (ZUEC, Campinas, SP), da Coleção Científica de Mamíferos, Universidade Federal de Santa Catarina(UFSC, Florianópolis, SC) e do Museu de Zoologia, Pontifícia Universidade Católica do Paraná (MZPUC/PR, Curitiba, PR) como detalhado no Anexo I. A escolha dos espécimes nessas coleções foi dirigida para obter a maior distribui- ção geográfica possível para cada espécie. O ordenamento taxonômico utilizado segue a Lista Anotada dos Mamíferos do Brasil elaborada por Fonseca et al. (1996).

\section{Procedimentos}

Os procedimentos utilizados na coleta, limpeza e preparação de pêlos-guarda, tanto para observação da cutícula quanto para observação da medula, são descritos resumidamente a seguir ( $c f$. Quadros \& Monteiro-Filho 2006). Os tufos de pêlos foram coletados com os dedos, da região de intersecção da linha mediana com a linha da cintura escapular no dorso dos espécimes. Os pêlos-guarda com bulbo e ápice foram separados das amostras, lavados em álcool comercial e secados em papel absorvente. Sobre uma lâmina de vidro limpa foi espalhada uma fina camada de esmalte para unhas, que foi deixada secar por 15 a 20 minutos. Então, os pêlos-guarda foram colocados sobre o esmalte e prensados com auxílio de uma morsa para que se obtivesse a impressão cuticular. A seguir foram retirados do esmalte através da extremidade distal esfregando gentilmente com a ponta do dedo. Para observação da medula, os pêlos retirados foram embebidos em água oxigenada cremosa 30 volumes, comercial, de uso cosmético, por 80 minutos (pêlos espessos foram cortados no escudo duas a três vezes para essa etapa). Em seguida foram lavados em água e secados em papel absorvente. Lâminas permanentes foram montadas com meio de montagem sintético transparente e lamínula.

\section{RESULTADOS}

\section{Padróes cuticulares na haste dos pélos-guarda}

Foram definidos 15 padrões cuticulares através da combinação de seis caracteres em seus diversos estados, como detalhado a seguir, resumido na tabela I e ilustrado nas figuras 1-15.

\section{Quanto ao imbricamento das bordas das escamas}

Imbricada - as escamas cuticulares dispõem-se com a borda livre (distal) dirigida para o ápice do pêlo. A borda livre de uma escama sobrepõe-se à borda aderida (proximal) da escama seguinte, como telhas num telhado.

Pavimentosa - as escamas cuticulares não apresentam bordas livres e não há sobreposição entre bordas de escamas adjacentes, como ladrilhos em um assoalho ou azulejos na parede.

\section{Quanto à forma das escamas}

Folidácea - a forma das escamas lembra a encontrada em escamas de serpentes; e a superfície do pêlo assemelha-se à pele de uma cobra.

Conoidal - cada escama envolve todo o perímetro do pêlo, descrevendo um cone. A seqüência de cones axiais encaixados ao longo do comprimento do pêlo assemelha-se a uma pilha de copos. Apresenta muitas variações que são bem detalhadas por BENEDict (1957).

Losângica - as escamas apresentam forma losângica ou hexagonal. 


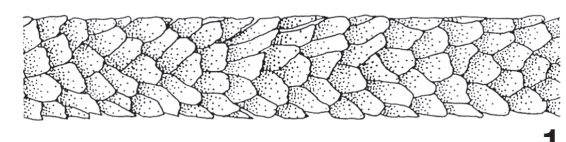

1

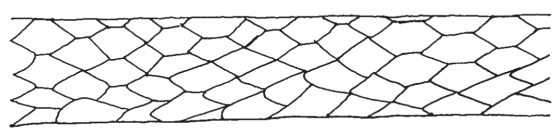

4

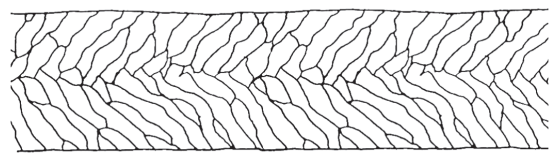

7

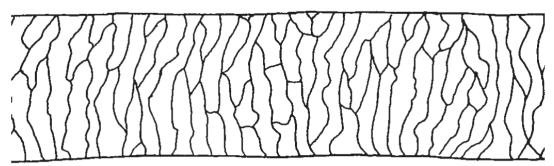

10

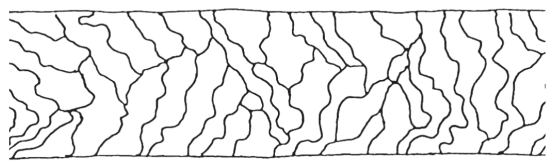

13
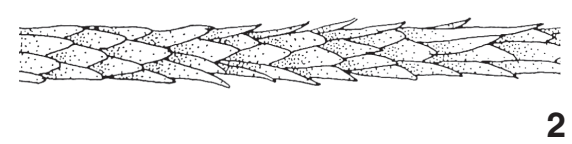

2

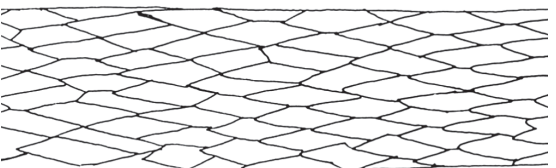

5
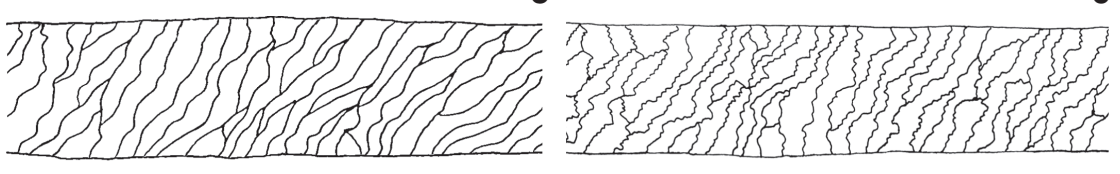

8
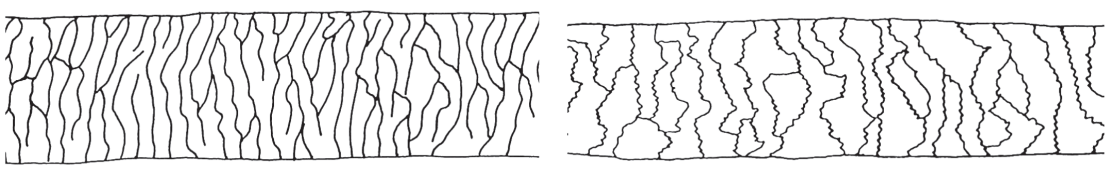

11

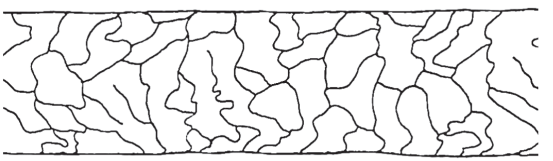

14
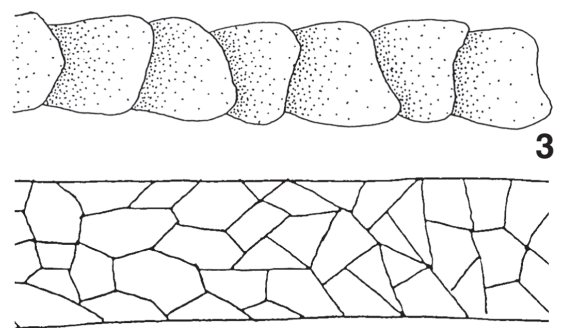

6

Figuras 1-15. Padrões da cutícula na haste dos pêlos-guarda de 64 espécies de mamíferos estudadas conforme a tabela I: (1) folidácea larga, (2) folidácea estreita, (3) conoidal, (4) losângica larga, (5) losângica estreita, (6) mosaico, (7) ondeada oblíqua dupla, (8) ondeada oblíqua simples, (9) ondeada oblíqua simples com as bordas das escamas ornamentadas, (10) ondeada transversal, (11) ondeada transversal com as bordas das escamas incompletas, (12) ondeada transversal com as bordas das escamas ornamentadas, (13) ondeada irregular, (14) ondeada irregular com as bordas das escamas incompletas, (15) ondeada irregular com as bordas das escamas ornamentadas.

Mosaico - as escamas têm formas poligonais com ângulos bem definidos, compondo um pavimento composto.

Ondeada - a forma das escamas não apresenta ângulos definidos; seu contorno é ondeado e compõe um conjunto de transições suaves entre saliências e reentrâncias de profundidades variáveis.

\section{Quanto à dimensão das escamas}

Larga - as escamas apresentam largura maior do que comprimento.

Intermediária - as escamas apresentam largura aproximadamente igual ao comprimento.

Estreita - as escamas apresentam comprimento maior do que largura.

Observa-se que quanto às dimensões das escamas, podem haver padrões intermediários entre os descritos aqui, que podem ser caracterizados de forma comparativa.

\section{Quanto à orientação das escamas}

Transversal - as escamas estão dispostas transversalmente em relação ao eixo longitudinal do pêlo.

Oblíqua simples - as escamas estão dispostas inclinadas, apenas para um lado, em relação ao eixo longitudinal do pêlo e não há uma linha central de divergência.

Oblíqua dupla - as escamas estão dispostas em diagonal com o eixo longitudinal do pêlo, divergindo a partir de uma linha central comum e inclinadas para os dois lados em direção às bordas do pêlo.

Irregular - há irregularidade na orientação das escamas, as quais ora se apresentam na transversal, ora oblíquas, e até mesmo longitudinais, ou seja, no sentido do maior eixo do pêlo. Nesse padrão o tamanho das escamas também varia.

\section{Quanto à ornamentação das bordas das escamas}

Lisa - as bordas são totalmente desprovidas de ornamentações.

Ornamentada - as bordas podem apresentar pequenas saliências e reentrâncias ondeadas, crenadas ou denteadas, a intervalos regulares ou não e com tamanhos variados.

Quanto à continuidade das bordas das escamas

Contínua - a linha da borda da escama é contínua, sem interrupções.

Descontínua - com interrupções que deixam a linha de algumas bordas com uma extremidade livre, ou seja, sem que esteja ligada à linha de outra borda. 
Tabela I. Sinopse dos caracteres e dos estados de caráter utilizados na caracterização dos padrões da cutícula na haste dos pêlos-guarda de 64 espécies de mamíferos estudadas (ver figura 1).

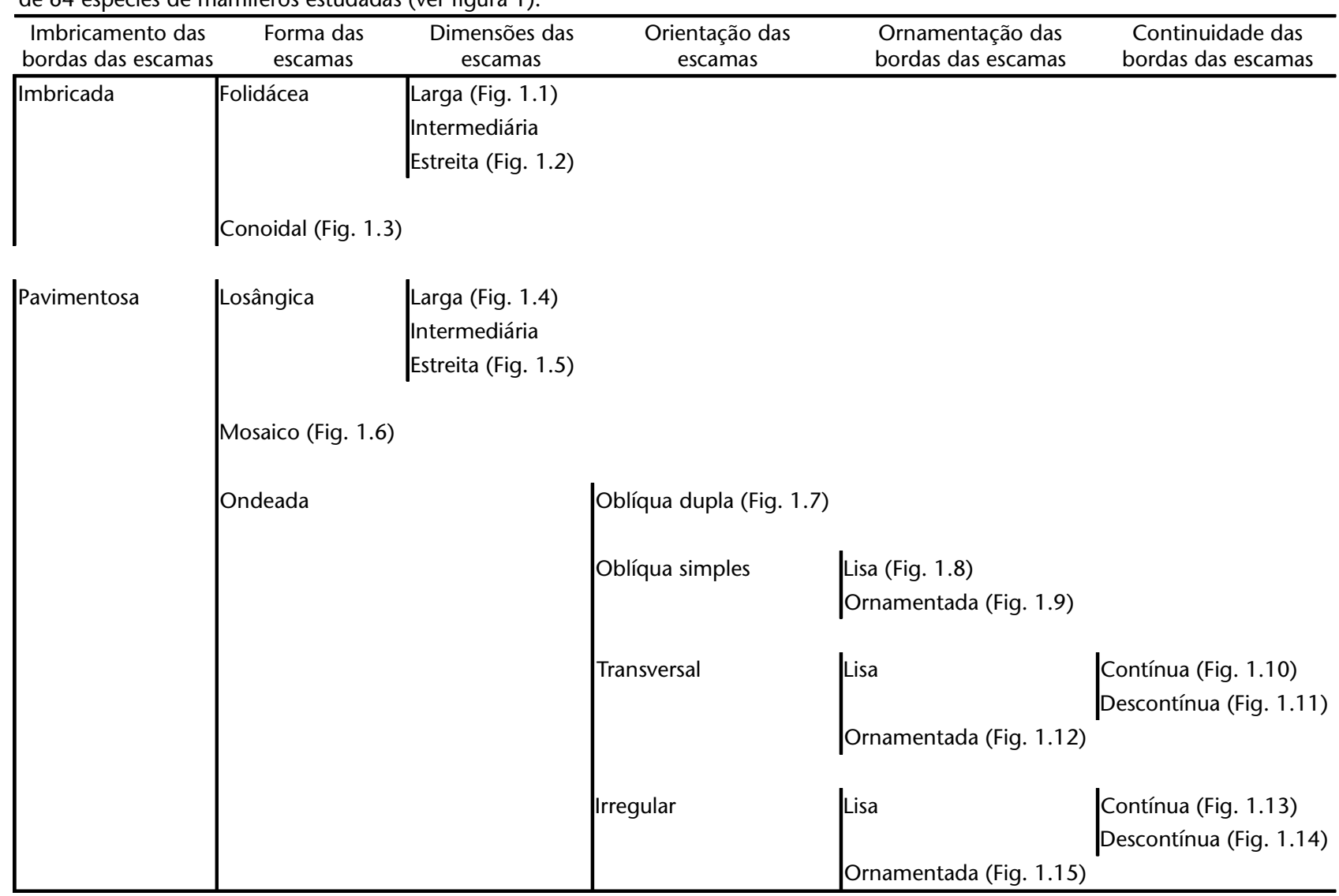

\section{Padróes medulares no escudo dos pélos-guarda}

Para a definição dos padrões medulares foram utilizados seis caracteres, em seus diversos estados, totalizando a ocorrência de 17 padrões. As descrições são apresentadas a seguir, resumidas na tabela II e ilustradas nas figuras 16-32.

\section{Quanto à presença}

Ausente - a medula pode estar ausente ao longo de todo o comprimento do pêlo ou apenas nos terços proximal e distal; quando isto ocorre não é possível discernir células medulares e o córtex homogêneo, ocupa todo o interior do pêlo. Cabe ressaltar, a necessidade de discernir a pigmentação cortical, que se caracteriza por grânulos de pigmento dispersos no córtex; das células medulares, que apresentam parede celular individualizando-as e separando-as do córtex.

Presente - mais comumente a medula está presente ao longo do comprimento do pêlo e é possível discernir as células medulares, contendo ar e pigmentos imersos no centro da matriz cortical. Quanto à continuidade

Descontínua - ao longo de todo o pêlo ou apenas nos terços proximal e distal, a medula pode apresentar interrup- ções. Nos espaços onde é interrompida há preenchimento pela matriz cortical.

Contínua - há continuidade na disposição das células medulares ao longo do comprimento do pêlo.

\section{Quanto ao número de fileiras de células}

Unisseriada - observando a medula em sua largura, notase que há apenas uma fileira de células.

Multisseriada - observando a medula em sua largura, nota-se que há duas ou mais fileiras de células.

\section{Quanto à disposição das células}

Justapostas - as paredes de células adjacentes estão em contato, restando pouca ou nenhuma matriz cortical entre elas.

Isoladas - há um espaço preenchido por córtex entre as células, individualizando-as.

Anastomosadas - há fusões entre as células formando arranjos celulares que podem delimitar espaços de córtex com forma e tamanho variados.

\section{Quanto à ornamentação da margem}

Íntegra - as margens da medula são lisas a o limite com o córtex é uma linha reta contínua. 


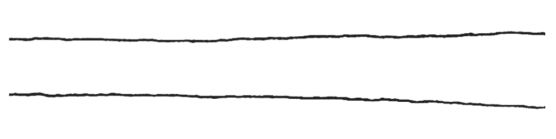

16
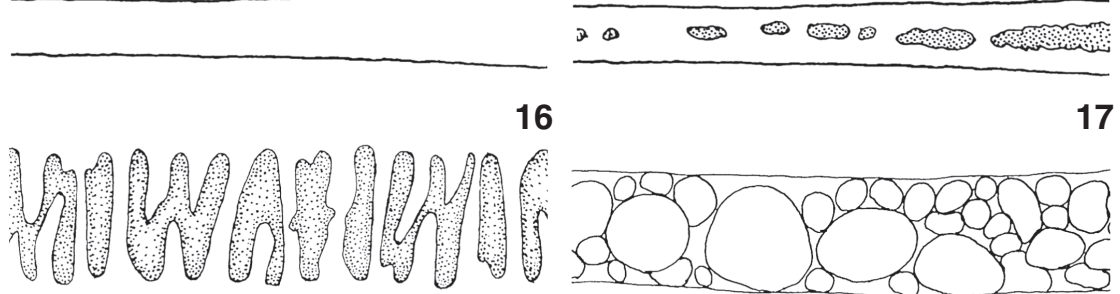

19

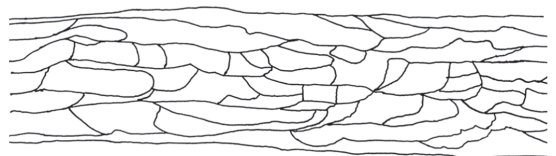

22
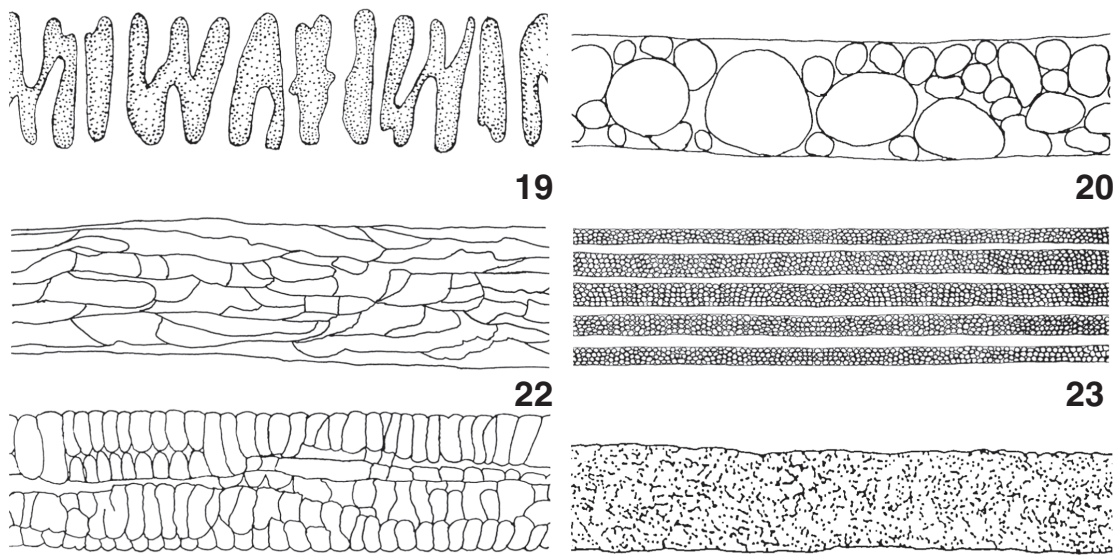

20

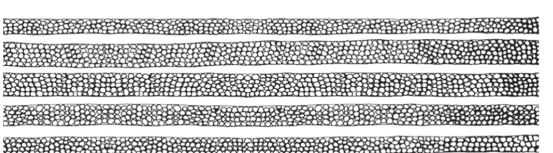
m.t.

23

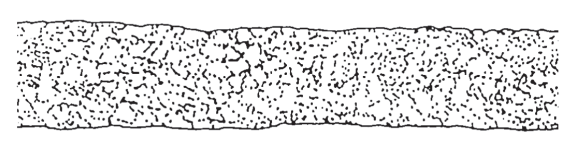

25

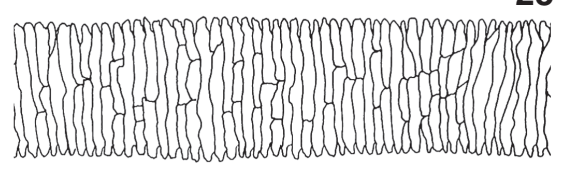

28

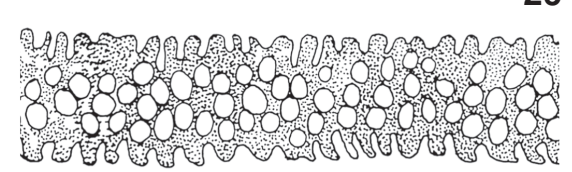

26

29

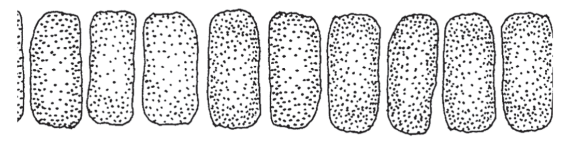

18

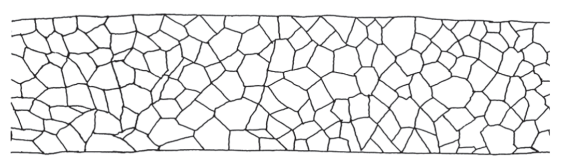

21

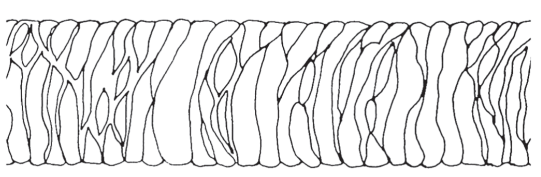

24
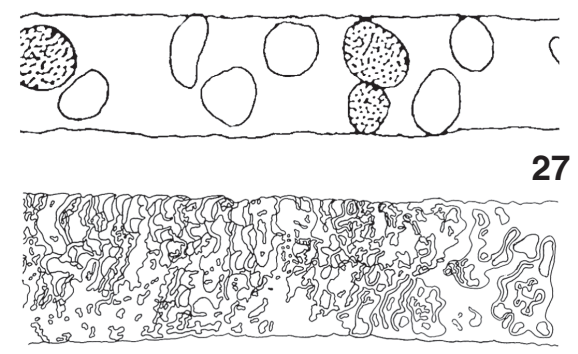

30

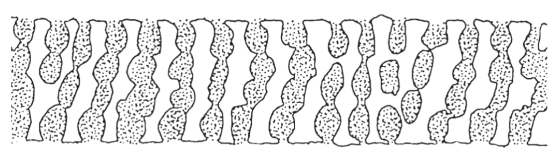

31

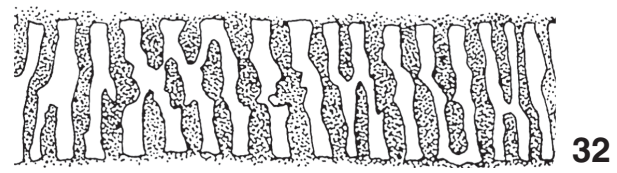

Figura 2. Padrões da medula no escudo dos pêlos-guarda de 64 espécies de mamíferos estudadas conforme a tabela II: (16) ausente, (17) descontínua, (18) unisseriada escalariforme, (19) unisseriada literácea, (20) anisocélica, (21) poligonal, (22) glandular, (23) cordonal, (24) fusiforme, (25) miliforme, (26) amorfa, (27) matricial, (28) trabecular, (29) reticulada, (30) crivada, (31) alveolar, (32) listrada.

Crenada - as margens da medula apresentam saliências semicirculares, adjacentes e contínuas, que se projetam invadindo o córtex. Nesse caso o limite com o córtex é uma linha crenada.

Crespa - as margens da medula apresentam saliências e reentrâncias de formas e tamanhos variados, que se projetam invadindo o córtex, e confere aspecto áspero à linha limite entre o córtex e a medula.

Fimbriada - as margens da medula apresentam muitas saliências e reentrâncias estreitas, com profundidades variáveis e distribuição irregular ao longo das margens, constituindo uma franja.

Ondeada - as saliências e reentrâncias são largas, profundas e distribuídas irregularmente ao longo das margens; na divisa entre a medula e o córtex, forma-se uma linha irregularmente ondeada.

Tracejada - as margens da medula são lisas e interrompidas a intervalos mais ou menos regulares; o limite da medula com o córtex é uma linha reta tracejada.

Revista Brasileira de Zoologia 23 (1): 279-292, março 2006

\section{Quanto à forma das células}

Escalariforme - há apenas uma única fileira de células aproximadamente retangulares e transversais em relação ao maior eixo do pêlo. Ocorre uma disposição seqüencial linear e com espaçamento regular das células, havendo lacunas entre elas preenchidas por córtex. Dessa forma assemelha-se a uma escada, na qual os degraus são os intervalos entre as células.

Literácea - as células têm disposição diagonal ao maior eixo do pêlo e devido ao contato dessas com as células vizinhas formam-se estruturas morfológicas semelhantes a algumas letras do alfabeto romano (por exemplo, H, N, M, Y), aqui denominadas de literóides.

Anisocélica - as células têm forma semelhante, mas tamanhos diferentes e podem atingir o diâmetro da medula.

Poligonal - células com forma poligonal, comprimidas umas contra as outras; o espaço intercelular é bastante reduzido. A disposição das células assemelha-se à disposição de ladrilhos em um assoalho. Quando as células têm aproximadamente a 
Tabela II. Sinopse dos caracteres e dos estados de caráter utilizados na caracterização dos padrões da medula no escudo dos pêlos-guarda de 64 espécies de mamíferos estudadas (ver figura 2).

\begin{tabular}{|c|c|c|c|c|c|}
\hline $\begin{array}{l}\text { Presença da } \\
\text { medula }\end{array}$ & $\begin{array}{c}\text { Continuidade da } \\
\text { medula }\end{array}$ & $\begin{array}{l}\text { Fileiras de } \\
\text { células }\end{array}$ & $\begin{array}{l}\text { Disposição das } \\
\text { células }\end{array}$ & $\begin{array}{l}\text { Forma das } \\
\text { células }\end{array}$ & $\begin{array}{l}\text { Ornamentação da } \\
\text { margem da medula }\end{array}$ \\
\hline $\begin{array}{l}\text { Ausente (Fig. 2.1) } \\
\text { Presente }\end{array}$ & $\begin{array}{l}\text { Descontínua (Fig. 2.2) } \\
\text { Contínua }\end{array}$ & $\begin{array}{l}\text { Unisseriada } \\
\text { Multisseriada }\end{array}$ & |Justapostas & 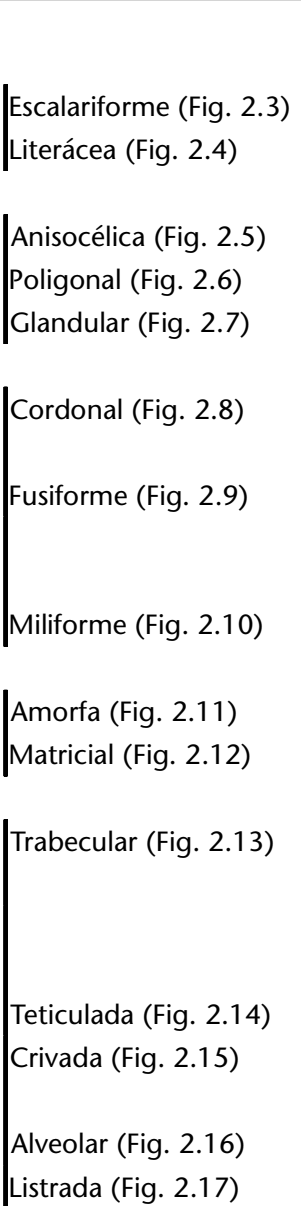 & $\begin{array}{l}\text { |Íntegra } \\
\text { |íntegra } \\
\text { |Crenada } \\
\text { Crespa } \\
\text { |íntegra } \\
\text { |ĺntegra } \\
\text { Ondeada } \\
\text { Fimbriada } \\
\text { Ondeada } \\
\text { Oracejada }\end{array}$ \\
\hline
\end{tabular}

mesma forma e tamanho diz-se poligonal regular, quando as células variam em tamanho e forma diz-se poligonal irregular.

Glandular - células alongadas no sentido do maior eixo do pêlo e comprimidas umas contra as outras, formando arranjos celulares semelhantes a glândulas acinares agrupadas em cordões longitudinais.

Matricial - há uma matriz amorfa de células fusionadas onde pode-se distinguir poucas células circulares a ovais, de tamanhos variados.

Cordonal - feixes longitudinais de células, pequenas e numerosas, separados entre si por lamelas de córtex.

Fusiforme - as células no centro da medula têm forma de fuso e as das margens são naviculares, podendo estar entremeadas com células que atravessam totalmente a medula no sentido transversal do pêlo e são aproximadamente botuliformes. As células podem estar orientadas em linhas levemente abaula- das em relação ao maior eixo do pêlo.

Miliforme - células retangulares com os bordos arredondados a aproximadamente elípticas, dispostas em duas ou mais fileiras longitudinais; a disposição das células assemelha-se a grãos de milho em uma espiga.

Amorfa - as células são muito pequenas, numerosas, e apresentam-se bastante anastomosadas. É difícil distinguir o limite entre elas, dando a aparência de uma massa amorfa.

Trabecular - as células são achatadas como tabiques ou trabéculas e dispõem-se próximas e paralelas entre si, mas transversais ao maior eixo do pêlo. Ligando as trabéculas paralelas há anastomoses longitudinais.

Reticulada - apresenta mais que uma fileira de células na sua largura e as células anastomosam-se umas às outras circunscrevendo espaços de tamanho variado e forma predominantemente circular. Não há grânulos de pigmento nos espa- 
ços, que podem ser vistos claros no microscópio. Quanto mais larga é a medula, menores e mais numerosos são os espaços circunscritos. Há uma organização na distribuição dos espaços, dando aspecto homogêneo à rede. Na espessura há somente uma camada de células de forma que, regulando o foco micrométrico do microscópio, não é possível identificar outros planos de células acima ou abaixo do foco principal.

Crivada - como no padrão reticulado, a medula apresenta mais que uma fileira de células na sua largura e as células anastomosam-se umas às outras circunscrevendo espaços que não apresentam acúmulo de pigmento em seu interior. Quanto mais larga é a medula, menores e mais numerosos são os espaços circunscritos. Entretanto, o que diferencia este padrão é a irregularidade na distribuição dos espaços, o aspecto heterogêneo e a presença de mais de um plano de foco, ou seja, movendo o ajuste micrométrico é possível visualizar camadas de células abaixo e acima do foco principal. A sobreposição dessas camadas de células dificulta, para o tricólogo iniciante, a diferenciação desse padrão com o anterior.

Alveolar - a medula apresenta várias células na sua largura, que fundem-se e delimitam entre si espaços, como cavidades ou alvéolos, onde se acumulam grânulos de pigmento e são observados escuros ao microscópio. É semelhante ao padrão reticulado devido à regularidade dos espaços intercelulares limitados pelas células, mas difere deste por apresentar o acúmulo de pigmento nos alvéolos. $\mathrm{O}$ arranjo das células e alvéolos em linhas transversais ao eixo maior do pêlo pode se apresentar ligeiramente abaulado.

Listrada -semelhante ao padrão alveolar. Entretanto, as cavidades estão alinhadas em filas transversais ao maior eixo do pêlo e fundem-se formando barras transversais que delimitam espaços contínuos, também transversais, com grânulos de pigmento. Esse arranjo celular fornece o padrão de barras claras e escuras alternadas como nos uniseriados escaleriformes, mas nitidamente diferente destes por ser multiseriado.

\section{DISCUSSÃO}

Uma retrospectiva das nomenclaturas propostas por vários autores para padrões de medula e cutícula encontra-se transcrita de forma comparativa com o presente estudo nas tabelas III e IV, respectivamente. Denota-se que a tendência dos trabalhos que propuseram nomenclaturas para pêlos, ao longo dos últimos 80 anos, foi de aumento do número de padrões descritos, especialmente para padrões medulares. No entanto, nos padrões medulares, como nos cuticulares, há evidências de várias sinonímias, ou seja, o que é o mesmo padrão de acordo com as ilustrações e descrições dos autores recebeu nomes diferentes. O oposto também foi verificado, pois há padrões morfologicamente distintos que receberam o mesmo nome dado por diferentes autores. Nesse sentido, a discussão a seguir detalha as principais questões nomenclatórias observadas.

Os padrões imbricados já foram ilustrados por outros autores como sendo diferentes dos padrões com arranjo pavimentoso das escamas cuticulares (HAUSMAn 1920, BRunNer \& Coman 1974, Teerink 1991). Entretanto, não foram descritos com a definição de imbricamento das escamas apresentada aqui, o que facilita a sua diagnose.

Perrin \& CAmpbell (1980) referem-se ao padrão pavimentoso ondeado transversal, como "mosaic", o que discordamos, assim como a maioria dos autores que consideram ondeados os padrões onde os bordos das escamas descrevem ondas, ao passo que no mosaico os bordos das escamas são retos e convergem para ângulos bem definidos.

Hausman (1920) une vários padrões diferentes em uma mesma categoria ("crenate") por não observar o caráter forma das escamas independente das bordas crenadas das escamas, perdendo assim informação diagnóstica útil na diferenciação das espécies. Além disso, as descrições dos padrões são pouco precisas e as ilustrações rudimentares, o que dificulta o entendimento da maioria dos padrões propostos.

Benedict (1957) estudou os padrões cuticulares dos quirópteros, definindo-os como "coronal" e incluiu nestes, em alguns casos, padrões ondeados pavimentosos transversais. Isso contraria a premissa, por ele mesmo estabelecida, de que nos padrões coronais apenas uma escama envolve todo o diâmetro do pêlo. No presente estudo, embora a semelhança entre certos padrões ondeados transversais e alguns coronais descritos por BENEDict (1957) tenha sido evidente, foi adotado o critério de cada escama circundar todo o diâmetro do pêlo e apresentar bordas imbricadas para caracterizar o padrão conoidal que corresponde aos "coronals" de Benedict (1957).

Os padrões "chevron" descritos por Perrin \& Campbell (1980) e Keogh (1985) foram incluídos no presente trabalho como variações dos ondeados onde as escamas são acentuadamente mais largas do que longas e, por conseqüência, suas bordas tornam-se muito próximas. O estudo da cutícula da haste dos pêlos-guarda mostrou que este padrão é raro nessa porção e é mais comum no escudo, onde a cutícula é menos diagnóstica (TEERINK 1991).

O caráter continuidade das bordas das escamas não foi observado por outros autores. É possível que tenha sido interpretado como uma falha na impressão do limite entre uma escama e outra durante a elaboração das lâminas de impressões cuticulares. Entretanto, no presente trabalho foram feitas repetidas e cuidadosas observações desse padrão para a certificação de tratar-se de caráter morfológico útil na caracterização da cutícula dos pêlos e não um artefato indesejável da técnica.

Quanto à ornamentação das bordas das escamas, BRUNNER \& Coman (1974), Perrin \& Campbell (1980), Keogh (1985) e Teerink (1991) diferenciaram até quatro tipos de ornamentações que foram úteis na diferenciação entre espécies. No presente estudo, não foi necessário diferenciar estes tipos de ornamentações e este caráter deverá ser detalhado em estudos futuros para otimizar a identificação de espécies semelhantes, pois forneceu bons resultados àqueles tricólogos.

Entre os autores que fizeram descrições e sugeriram no-

Revista Brasileira de Zoologia 23 (1): 279-292, março 2006 
Tabela III. Nomenclatura proposta no presente estudo para os padrões medulares baseados no caractere forma das células da medula e a correspondência com a nomenclatura proposta por outros autores.

\begin{tabular}{|c|c|c|c|c|c|c|c|}
\hline Este estudo & TEERINK (1991) & KEOGH (1983) & KelLer (1980) & $\begin{array}{c}\text { BRUNNER \& COMAN } \\
(1974)\end{array}$ & $\begin{array}{l}\text { APPELYARD } \\
(1960)\end{array}$ & МАТНIAK (1938) & $\begin{array}{l}\text { HAUSMAN } \\
(1920)\end{array}$ \\
\hline descontínua & interrupted & - & - & $\begin{array}{l}\text { interrupted e } \\
\text { fragmental }\end{array}$ & $\begin{array}{l}\text { interrupted e } \\
\text { fragmental }\end{array}$ & fragmental & fragmental \\
\hline escalariforme & ladder & uniserial ladder & en échelons & uniserial ladder & $\begin{array}{l}\text { uni-serial } \\
\text { ladder }\end{array}$ & discontinuous & $\begin{array}{l}\text { discontinuous } \\
\text { simple }\end{array}$ \\
\hline literácea & $\begin{array}{l}\text { unicellular } \\
\text { irregular }\end{array}$ & - & - & - & - & - & - \\
\hline anisocélica & - & - & - & - & - & - & - \\
\hline poligonal & filled & $\begin{array}{l}\text { wide medulla } \\
\text { lattice }\end{array}$ & réticulée & wide medulla lattice & lattice & - & - \\
\hline glandular & - & - & - & - & - & - & - \\
\hline cordonal & - & - & - & - & - & - & - \\
\hline fusiforme & - & - & - & - & - & - & - \\
\hline miliforme & $\begin{array}{l}\text { multicelular in } \\
\text { rows }\end{array}$ & - & en colonnes & multiserial ladder & - & chambered & - \\
\hline amorfa & intermediate & - & - & simple & fine lattice & - & - \\
\hline matricial & - & - & - & - & - & - & - \\
\hline trabecular & $\begin{array}{l}\text { reversed cloisonné } \\
\text { e cloisonné }\end{array}$ & 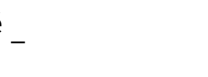 & cloisonnée & narrow medulla lattice & - & - & - \\
\hline reticulada & - & - & en treillis & - & - & - & - \\
\hline crivada & - & - & réticulée & - & - & - & - \\
\hline alveolar & crescent & - & - & wide aeriform lattice & - & compound & $\begin{array}{l}\text { discontinuos } \\
\text { compound }\end{array}$ \\
\hline listrada & isolated & - & - & - & - & - & - \\
\hline- & - & - & - & globular & - & - & - \\
\hline- & - & - & - & stellate & stellate & - & - \\
\hline- & - & - & - & intruding & - & - & - \\
\hline- & - & - & noduleuse & - & - & - & - \\
\hline
\end{tabular}

Tabela IV. Nomenclatura proposta no presente estudo para os padrões cuticulares baseados nos caracteres forma das escamas e orientação das escamas e a correspondência com a nomenclatura proposta por outros autores.

\begin{tabular}{|c|c|c|c|c|c|c|c|}
\hline Este estudo & $\begin{array}{l}\text { TEERINK } \\
(1991)\end{array}$ & $\begin{array}{c}\text { KEOGH } \\
(1983,1985)\end{array}$ & KeLLeR (1980) & $\begin{array}{c}\text { PerRIN \& } \\
\text { CAMPBELL } \\
(1980)\end{array}$ & $\begin{array}{c}\text { BRUNNER \& } \\
\text { CoMAN (1974) }\end{array}$ & $\begin{array}{l}\text { ApPeLYYARD } \\
(1960)\end{array}$ & HAUSMAN (1920) \\
\hline folidáceo & petal & petal & en facettes & petal & petal & $\begin{array}{l}\text { irregular } \\
\text { petal }\end{array}$ & $\begin{array}{l}\text { imbricate ovate, } \\
\text { acuminate e elongate }\end{array}$ \\
\hline conoidal & - & coronal & coronal & coronal & simple coronal & - & $\begin{array}{l}\text { coronal simple e } \\
\text { serrate }\end{array}$ \\
\hline losângico & $\begin{array}{l}\text { diamond } \\
\text { petal }\end{array}$ & $\begin{array}{l}\text { pectinate e } \\
\text { diamond petal }\end{array}$ & lancéolée & pectinate & diamond petal & $\begin{array}{l}\text { diamond } \\
\text { petal }\end{array}$ & coronal dentate \\
\hline mosaico & mosaic & regular mosaic & - & - & mosaic & mosaic & - \\
\hline $\begin{array}{l}\text { ondeado } \\
\text { oblíquo duplo }\end{array}$ & - & $\begin{array}{l}\text { single chevron - } \\
\text { deep }\end{array}$ & - & - & - & - & - \\
\hline $\begin{array}{l}\text { ondeado } \\
\text { oblíquo simples }\end{array}$ & - & - & - & - & - & - & - \\
\hline $\begin{array}{l}\text { ondeado } \\
\text { transversal }\end{array}$ & regular wave & $\begin{array}{l}\text { regular waved } \\
\text { mosaic }\end{array}$ & $\begin{array}{l}\text { en mosaic e } \\
\text { pavimenteuses }\end{array}$ & $\begin{array}{l}\text { flattened } \\
\text { mosaic }\end{array}$ & regular waved & $\begin{array}{l}\text { regular } \\
\text { waved }\end{array}$ & imbricate flattened \\
\hline $\begin{array}{l}\text { ondeado } \\
\text { irregular }\end{array}$ & $\begin{array}{l}\text { irregular } \\
\text { wave }\end{array}$ & $\begin{array}{l}\text { irregular waved } \\
\text { mosaic e chevron }\end{array}$ & chevrons & - & irregular waved & $\begin{array}{l}\text { irregular } \\
\text { waved }\end{array}$ & - \\
\hline
\end{tabular}


menclaturas para padrões cuticulares apenas TEERINK (1991) abordou a orientação das escamas cuticulares. Ainda assim, a interpretação do referido autor do que seja a orientação das escamas em relação ao eixo maior do pêlo se confunde com as dimensões (largura e comprimento) das escamas. Quando o autor se refere aos estados de caráter "transversal", "longitudinal" e "intermediate" das escamas cuticulares, está fazendo menção à proporção entre a largura e o comprimento das escamas, o que se reflete na sua orientação em relação ao maior eixo do pêlo. No presente trabalho, por outro lado, os estados de caráter da orientação das escamas (irregular, transversal, oblíqua simples e oblíqua dupla) dizem respeito apenas à sua orientação em relação ao eixo longitudinal do pêlo, não têm relação com as dimensões das escamas e são aplicados apenas ao padrão ondeado.

A distância entre as bordas das escamas comumente utilizada na caracterização microestrutural de pêlos-guarda (Brunner \& Coman 1974, Perrin \& Campbell 1980, Keogh 1985, TEERINK 1991) não foi utilizada no presente trabalho por não ser útil à diagnose das espécies estudadas. Observou-se que quanto mais para a porção distal mais próximas as bordas das escamas em todas as espécies estudadas e que, considerando-se apenas a haste, a distância entre as bordas das escamas foi semelhante entre espécies diferentes.

O caráter continuidade da medula utilizado no presente trabalho em dois estados, medula contínua e descontínua, está de acordo com Teerink (1991) e Hausman (1920). Brunner \& Coman (1974) diferenciaram três tipos de medula, a contínua e duas descontínuas ("fragmental" e "interrupted"), de acordo com a quantidade de córtex entre um fragmento e outro de medula. Em nosso estudo, a descontinuidade da medula foi observada em um número reduzido de espécies e não foram observados dois padrões. Entretanto, em estudos futuros, envolvendo mais espécies de mamíferos brasileiros, é possível que haja necessidade, e possibilidade, de diferenciar outros padrões de medulas descontínuas.

Hausman (1920), BRunner \& Coman (1974) e TEerink (1991), embora tenham atribuído nomes diferentes, foram unânimes em dividir os padrões medulares em duas grandes categorias: medula com uma fileira de células e medula com duas ou mais fileiras de células. O presente estudo concorda com estas categorias, tendo sido possível observar essa divisão (medula unisseriada e multisseriada). A medula unisseriada literácea foi descrita apenas por TEerink (1991) que a denominou "unicelular irregular". O mesmo autor havia descrito a medula alveolar e a denominou "isolated". As medulas multisseriadas reticulada, crivada, anisocélica, fusiforme, matricial, glandular e cordonal não possuem descrições anteriores análogas na literatura, sendo algumas delas típicas de espécies de mamíferos neotropicais até o momento.

O único autor que havia considerado as margens da medula como um caráter importante na caracterização morfológica de pêlos de mamíferos foi TEerink (1991). Este autor descreveu três tipos de margens ("straight", "fringed", "scalloped") e ob- servou sua importância na diagnose de algumas famílias de mamíferos. O presente estudo descreve seis padrões de margens da medula, que são um reflexo da forma das células da fileira que fica em contato com o córtex, e que também tiveram importância na diagnose de famílias.

No presente trabalho, foram descritos e nomeados os padrões microestruturais cuticulares e medulares encontrados em 64 espécies de mamíferos brasileiros. Esse número representa apenas uma fração do total de mamíferos conhecidos no Brasil, 524 espécies de acordo com Fonseca et al. (1996). Portanto, à medida que o estudo da microestrutura de pêlos-guarda de mamíferos difunda-se em outras regiões do país aumentando o número de espécies estudadas, outros caracteres e estados de caráter deverão ser descritos e nomeados.

\section{AGRADECIMENTOS}

A Sandra B. Mikich pela leitura cuidadosa do manuscrito e sugestões importantes. A Fernando C. Straube pelo cuidado e especial atenção na revisão do manuscrito. A Liliani M. Tiepolo pela revisão das citações bibliográficas. À Mülleriana: Sociedade Fritz Müller de Ciências Naturais e ao Instituto de Pesquisas Cananéia (IPeC) pelo apoio institucional. Aos órgãos financiadores dessa pesquisa, CAPES e CNPq.

\section{REFERÊNCIAS BIBLIOGRÁFICAS}

ApPlEyard, H.M. 1960. Guide to the identification of animal fibres. Leeds, Wool Industries Research Association, 124p. BENEDICT, F.A. 1957. Hair structure as a generic character in bats. University of California Publications in Zoology, Berkley, 59: 285-548.

BRunner, H. \& B.J. Coman. 1974. The identification of mammalian hair. Melbourne, Inkata Press, 176p.

Chakraborty, R.; J.K. De \& S. Chakraborty. 1996. Identification of dorsal guard hairs of Indian species of the genus Panthera Oken (Carnivora: Felidae). Mammalia, Paris, 60: 473-480.

Charvet, C. \& A. Keller. 1989. Une méthode douce d’identification des mammifères: la structure fine des poils. Le Rhinolophe, Geneve, 6: 19-25.

Chehébar, C. \& S. Martín. 1989. Guía para el conocimiento microscópico de los pelos de los mamíferos de la Patagonia. Doñana Acta Vertebrata, Sevilla, 16: 247-291.

DAY, M.G. 1966. Identification of hair and feather remains in the gut and feaces of stoats and weasels. Journal of Zoology, London, 148: 201-217.

De, J.K.; S. Chakraborty \& R. Chakraborty. 1998. Identification of dorsal guard hairs of five indian species of mongoose, Herpestes Illiger (Mammalia: Carnivora). Mammalia, Paris, 62: 285-295.

Dennler, J.G. 1939. Morfografía de los pelos y la configuración del pelaje de mamíferos sudamericanos. Physis, Buenos Aires, 16: 207-223.

EMmons, L. \& F. FeER. 1997. Neotropical rainforest mammals: 
a field guide. Chicago, The University of Chicago Press, $307 p$.

FernÁndez, G.J.\& S.M. Rossi. 1998. Medullar type and cuticular scale patterns of hairs of rodents and small marsupials from the Monte Scrubland (San Luis Province, Argentina). Mastozoología Neotropopical, Tucumán, 5: 109-116.

Fonseca, G.A.B.; G. Hermann; Y.L.R. Leite; R.A. Mittermeier; A.B. Rylands \& J. L. Patton. 1996. Lista anotada dos mamíferos do Brasil. Conservation International. Occasional Papers in Conservation Biology, Washington, 3: 1-35.

Hausman, L.A. 1920. Structural characteristics of the hair of mammals. American Naturalist, Chicago, 54: 496-523.

Hershkovitz, P. 1977. Evolutionary and Comparative Morphology of New World Monkeys, Infraorder Platyrrhini, p. 67368. In: P. Hershkovitz (Ed.). Living New World monkeys (Platyrrhini). Chicago, The University of Chicago Press, 1132 p.

Hitton, H. \& N.P. Kutscha. 1978. Distinguishing characteristics of the hairs of eastern coyote, domestic dog, red fox and bobocat in Maine. American Midland Naturalist, Notredame, 100: 223-227.

Keller, A. 1978. Détermination des mammifères de la Suisse par leur pelage: I. Talpidae et Soricidae. Revue Suisse de Zoologie, Geneve, 85: 758-761.

Keller, A. 1980. Détermination des mammìferes de la Suisse par leur pelage: II. Diagnose des Families, III Lagomorpha et Rodentia. Revue Suisse de Zoologie, Geneve, 87: 781-796.

Keogh, H.J. 1983. A photographic reference system of the microstructure of the hair of southern african bovids. South African Journal of Wildlife Research, Stellenbosch, 13: 89-132.

Keogh, H.J. 1985. A photographic reference system based on the cuticular scale patterns and groove of the hair of 44 species of southern African Cricetidae and Muridae. South African Journal of Wildlife Research, Stellenbosch, 15: 109-159.

LOMULLER, L. 1924. Reconnaissance méthodique, à l'aide du microscope, des poils d'un certain nombre de mammifères. Essai de leur classification. Bulletin des Sciences Pharmacologiques, Paris, 10: 497-581.

Mathiak, H.A. 1938. A key to hairs of the mammals of southern Michigan. Journal of Wildlife Management, Bethesda, 2: 251-268.

MAYER, W.V. 1952. The hair of California mammals with keys to the dorsal guard hairs of California mammals. American Midland Naturalist, Notre Dame, 48: 480-512.

Moojen, J. 1952. Os Roedores do Brasil. Rio de Janeiro, Instituto Nacional do Livro, 214p.

OLI, M.K. 1993. A key for the identification of the hair of mammals of a snow leopard (Panthera uncia) habitat in Nepal. Journal of Zoology, London, 231: 71-93.
Oliveira, J.A.; M.L. Lorini \& V.G. Persson. 1992. Pelage variation in Marmosa incana (Didelphidae, Marsupialia) with notes on taxonomy. Zeitschrift für Säugetierkunde, Berlin, 57: 129-136.

Perrin, M.R. \& B.S. Campbell. 1980. Key to the mammals of the Andries Vosloo Kudu Reserve (eastern Cape), based on their hair morphology, for use in predator scat analysis. South African Journal of Wildlife Research, Stellenbosch, 10: 1-14.

Pough, F.H.; J.B. Heiser \& W.N. Mcfarland. 1999. A Vida dos Vertebrados. São Paulo, Athena Editora, $2^{\text {a }}$ ed., 839p.

Quadros, J. \& E.L.A. Monteiro-Filho. 2006. Coleta e preparação de pêlos de mamíferos para identificação em microscopia óptica. Revista Brasileira de Zoologia, Curitiba, 23 (1): 274 278.

Quadros, J. \& E.L.A. Monteiro-Filho. 1998a. Effects of digestion, putrefaction, and taxidermy processes on Didelphis albiventris hair morphology. Journal of Zoology, London, 244: 331334.

Quadros, J. \& E.L.A. Monteiro-Filho. 1998b. Morphology of different hair types of Didelphis albiventris and its usage in hair identification. Ciência e Cultura, São Paulo, 50: 382385 .

QuAdros, J. \& N.C. CÁCERES. 2001. Ecologia e conservação de mamíferos na Reserva Volta Velha, Estado de Santa Catarina, Brasil. Acta Biologica Leopoldensia, São Leopoldo, 23: 213-224.

RiggotT, J.M. \& E.H. Wyatt. 1980. Scanning electron microscopy of hair from different regions of the body of the rat. Journal of Anatomy, London, 130: 121-126.

Stains, H.J. 1958. Field key to guard hair of middle western furbearers. Journal of Wildlife Management, Bethesda, 22: 95-97.

TAYLOR, R.J. 1985. Identification of the hair of Tasmanian mammals. Papers and Proceedings of the Royal Society of Tasmania, Hobart, 119: 69-82.

TEERINK, B.J. 1991. Hair of west european mammals: atlas and identification. Cambridge, Cambridge University Press, $224 \mathrm{p}$.

Thompson, I.D.; M.S. Porter \& S.L. WALKer. 1987. A key to the identification of some small boreal mammals of central Canada from guard hairs. Canadian Field Naturalist, Ottawa, 101: 614-616.

Vázquez, D.E.; P.G. Perovic \& A.A. Olsen. 2000. Patrones cuticulares y medulares de pelos de mamíferos del noroeste argentino (Carnivora y Artiodactyla). Mastozoología Neotropical, Tucumán, 7: 131-142.

WALLIS, R.L. 1993. A key for the identification of guard hairs of some Ontario mammals. Canadian Journal of Zoology, Ottawa, 71: 587-591.

Wildman, A.B. 1954. The microscopy of animal textile fibres. Leeds, Wool Industries Research Association, 209p.

Recebido em 18.III.2005; aceito em 06.III.2006 
Anexo I. Material Examinado (646 espécimes de 64 espécies).

Didelphimorphia

Didelphidae

Caluromys philander (Linnaeus, 1758) ( $\mathrm{n}=13)$ - MHNCI: 931. MNRJ: 1231, 7831, 11673, 11723, 16121, $20964,20786,30562$. MZPUC/PR: 1105. ZUEC: 1242, 1520, 1241.

Chironectes minimus (Zimmerman, 1780) ( $\mathrm{n}=11)$ - MNR): 1280, 1282, 1283, 1285, 5897, 10507, 11184, 25739. UFSC: 2034, 2034. ZUEC: 1687.

Didelphis albiventris Lund, $1840(\mathrm{n}=43)$ - MHNCl: 357, 358, 359, 411, 412, 413, 414, 415, 423, 424, 425, 426, 716, 825, 1097, $1106,1734,1735,1736,1989,2655,2656,2658,2659,2660,2661,2663,2664,3409$. MNRJ: 4737, 4766, 8322, 17259, 22878, 22894, 23585, 23657, 23690, 30050. MZPUC/PR: 1143. ZUEC: 1274, 1214, 1709.

Didelphis aurita Wied-Neuwied, $1826(\mathrm{n}=46)$ - MHNCI: 17, 29, 114, 128, 129, 161, 172, 197, 205, 206, 207, 210, 223, 245, 246, 280, 281, 330, 331, 335, 337, 356, 408, 409, 427, 428, 652, 712, 848, 1737, 2068, 2654, 2657, 2662, 3143, 3144, 3145, 3151, 3152. MNRJ: 2948, 5641, 5808, 11321, 46511. UFSC: 96, 102.

Gracilinanus agilis (Burmeister, 1854) ( $\mathrm{n}=3$ ) - UFSC: 2430, 2583, 2429.

Gracilinanus microtarsus (Wagner, 1842) ( $\mathrm{n}=9$ ) - MHNCI: 1103, 2792, 2793. MZPUC/PR: 1110, 1112, 1114, 1120. UFSC: 2030, 3000.

Lutreolina crassicaudata (Desmarest, 1804) ( $\mathrm{n}=11)$ - MHNCI: 3747, 3748, CTX 285, CTX 3134. MNRJ: 20977, 24473. UFSC: 82, 602. ZUEC: 1398, 1499, 1610.

Marmosops incanus (Lund, 1840) ( $\mathrm{n}=7$ ) - MHNCI: 934, 935. MNRJ: 7221, 8666, 24687, 31467. ZUEC: 1797.

Metachirus nudicaudatus (Desmarest, 1817) $(\mathrm{n}=15)-\mathrm{MHNCl}: 2049,2066,2210 . \mathrm{MNR}): 5499,8200,11269,20228,26614$, 26889, 30571, 4279. MZPUC/PR: 1107. UFSC: 2803. ZUEC: 1772, 1379.

Micoureus demerarae (Thomas, 1905) $(\mathrm{n}=23)$ - MHNCI: 1732, 1749, 2598, 2791, 3149, 3150, 3165. MZPUC/PR: 1117, 1123, 1124, 1125, 1127. UFSC: 146, 147, 148, 149, 150, 434, 610, 741, 865, 2582. ZUEC: 1498.

Monodelphis americana (Müller, 1776) $(n=4)-\mathrm{MHNCl}$ : 3147, 3323. MNRJ: 7569, 11485.

Monodelphis domestica (Wagner, 1842) ( $\mathrm{n}=7$ ) - MNRJ: 16215, 16338, 16489, 16596, 17014, 46586, 46589.

Monodelphis iheringi (Thomas, 1888) $(\mathrm{n}=1)-\mathrm{MNRJ}$ : 10305.

Monodelphis scalops (Thomas, 1888) $(\mathrm{n}=1)-\mathrm{MNRJ}$ : 7248.

Monodelphis sorex (Hensel, 1872) ( $\mathrm{n}=6)$ - MHNCI: 3198, CTX 3205, CTX 3206, CTX 3229, CTX 3256, CTX 3262.

Philander frenata (Olfers, 1818) $(\mathrm{n}=26)-\mathrm{MHNCl}: 26,162,212,213,2029,2596,2597,3148,3333,3749,3750$. MNR): 5873, 26624, 30443. MZPUC/PR: 1101, 1102, 1104, 1111, 1113, 1118, 1119, 1121. UFSC: 757. ZUEC: 1357, 1522, 1698.

Xenarthra

Myrmecophagidae

Tamandua tetradactyla (Linnaeus, 1758) ( $\mathrm{n}=44)-\mathrm{MHNCl}$ : 20, 22, 134, 163, 249, 290, 315, 339, 406, 407, 1694, 1695, 2500, 2501, 2502, 2503, 2685, 2686, 2974, 3437. MNRJ: 2326, 2328, 2340, 2341, 3846, 5050, 5051, 5056, 5507, 5510, 5515, 5967, $7620,9677,9678,11607,23950,23951,24832,24833,24834,26851,28798,50820$.

Dasypodidae

Cabassous tatouay (Desmarest, 1804) ( $\mathrm{n}=4)$ - MNRJ: 1854, 4989, 10065, 23983.

Dasypus novemcinctus Linnaeus, 1758 ( $\mathrm{n}=12$ ) - MNRJ: 1504, 5006, 5969, 7593, 7597, 10059, 10092, 10114, 23995, 26917, 27945, 30687.

Dasypus septemcinctus Linnaeus, 1758 ( $n=6$ ) - MNRJ: 2366, 2370, 4291, 10091, 23989, 55053.

Euphractus sexcinctus (Linnaeus, 1758) ( $\mathrm{n}=10)$ - MNRJ: 1505, 4295, 4972, 4979, 5887, 10069, 10112, 23972, 24130. ZUEC: 1792. Primates

Cebidae

Cebus apella (Linnaeus, 1758) $(\mathrm{n}=23)-\mathrm{MHNCl}: 38,40,42,43,168,196,220,221,294,298,299,312,313,314,388,389,401$, $403,405,459,460,461,462$.

Carnivora

Canidae

Cerdocyon thous (Linnaeus, 1766) ( $\mathrm{n}=18)$ - MHNCl: 310, 1713, 1716, 2684, 2723, 3407, 3728. MNR): 3885, 4891, 25577, 25583, 25587, 25588, 25602, 32371. ZUEC: 1281, 1616, 1782.

Revista Brasileira de Zoologia 23 (1): 279-292, março 2006 
Procyonidae

Nasua nasua (Linnaeus, 1766) ( $\mathrm{n}=16)$ - MHNCl: 69, 227, 285, 286, 1855, 2551. MNRJ: 3062, 3876, 5502, 5925, 24779, 24783, 25900, 43925. MZUSP: 4983. ZUEC: 1615.

Procyon cancrivorus (G. Cuvier, 1798) ( $\mathrm{n}=13)$ - MHNCI: 369, 633, 737. MNRJ: 3878, 3880, 11203, 23884, $23885,23887,25674$. MZUSP: 5559. ZEUC: 1369, 1641.

Mustelidae

Lontra longicaudis (Olfers, 1818) ( $\mathrm{n}=10)$ - MHNCI: 1101, 1698, 2691. MNRJ: 3020, 4894, 22255, 25682, $25728,28999,50798$.

Eira barbara (Linnaeus, 1758) $(\mathrm{n}=13)$ - MHNCI: 66, 226, 288, 490. MNR): 3105, 3112, 4907, 5619, 5959, 29978, 30004. MZUSP: 5181.

Galictis cuja (Molina, 1782) ( $\mathrm{n}=7$ ) - MHNCl: 62, 1302, 2795, 2796. ZUEC: 1226, 1454, 1746.

Felidae

Herpailurus yaguarondi (Lacépède, 1809) ( $\mathrm{n}=16)-\mathrm{MHNCl}$ : 855, 1250. MNRJ: 1039, 4256, 4893, 11599, 24885, 24901, 25721, 33513. UFSC: 0343, 0390, 0392. ZUEC: 90, 1222, 1286.

Leopardus pardalis (Linnaeus, 1758) ( $\mathrm{n}=11)$ - MHNCI: 44, 46. MNRJ: 4812, 7628, NC1991. UFSC: 0393, $0441,0437,0439,0440$. ZUEC: 1297.

Leopardus tigrinus (Schreber, 1775) ( $\mathrm{n}=14)$ - MHNCl: 2679, 3402. MNRJ: 3158, 3137, 3889, 24894, 24895, 24896, 25722, 30025, 44359. UFSC: 0331. ZUEC: 1298, 1503.

Leopardus wiedii (Schinz, 1821) ( $n=7)-\mathrm{MHNCl}$ : 2676. MNRJ: 3890, 4816, 5621, 18813. MZUSP: 439, 2920.

Puma concolor (Linnaeus, 1771) ( $n=4)-\mathrm{MHNCl}$ : 385, 1846. MNRJ: 24873. UFSC: 0387.

Artiodactyla

Cervidae

Mazama americana (Erxleben, 1777) ( $\mathrm{n}=9$ ) - MHNCI: 91, 146, 148, 149, 150, 151, 152, 153, 154.

Mazama gouazoupira (G. Fischer, 1814) ( $\mathrm{n}=6)$ - MHNCI: 519, 520, 2739, 2787, 2788. MNR): 54797.

Mazama nana (Hensel, 1872) ( $\mathrm{n}=5$ ) - MHNCI: 2513, 2687, 2700, 2702. MNRJ: 54803.

Tayassuidae

Pecari tajacu Linnaeus, 1758 ( $\mathrm{n}=10)$ - MHNCI: 140, 237, 300, 343, 344, 345. MNRJ: 5453, 28795, 37078. ZUEC: 1299.

Perissodactyla

Tapiridae

Tapirus terrestris (Linnaeus, 1758) ( $\mathrm{n}=1)$ - MNRJ: MF23.

Rodentia

Sciuridae

Sciurus aestuans Linnaeus, 1766 ( $n=10)$ - MNRJ: 1910, 3807, 6418, 8196, 11178, 11668, 11900, 20605, $24303,24534$.

Hydrochaeridae

Hydrochaeris hydrochaeris (Linnaeus, 1766) ( $\mathrm{n}=4$ ) - MNRJ: 24296, 36715, 36776, 43501.

Agoutidae

Agouti paca (Linnaeus, 1766) ( $\mathrm{n}=10)$ - MNRJ: 908, 4871, 4878, 4882, 7255, 11208, 24273, 24279, 26930. ZUEC: 1429.

Dasyproctidae

Dasyprocta azarae Lichtenstein, 1823 ( $\mathrm{n}=6$ ) - MNRJ: 4854, 4859, 34185, 34387, 43169, 43172.

Caviidae

Cavia aperea Erxleben, $1777(n=23)$ - MNR): 1366, 2609, 4327, 4476, 4479, 5256, 5416, 5421, 6741, 7558, 8231, 10025, 22243, 24369, 24653, 25014, 43220, 43282, 43300, 43301. ZUEC: 1392, 1504, 1733.

Myocastoridae

Myocastor coypus (Molina, 1782) ( $\mathrm{n}=2)$ - MNRJ: 46939, 46940.

Echimyidae

Trinomys dimidiatus (Günther, 1877) $(\mathrm{n}=2)-\mathrm{MNRJ}$ : 33731, 33738.

Trinomys iheringi Thomas, $1911(\mathrm{n}=3)$ - ZUEC: 1252, 1253, 1386.

Euryzygomatomys spinosus (G. Fischer, 1814) ( $\mathrm{n}=6)$ - MNRJ: 4029, 6777, 13419, 24147, 24152, 33709.

Kannabateomys amblyonyx (Wagner, 1845) ( $n=4)$ - MNR): 31577, 31578. ZUEC: 1411, 1789. 
Echimys dasythrix (Hensel, 1872) ( $\mathrm{n}=3)$ - MNRJ: 31568. UFSC: 2778.

Erethizontidae

Coendou prehensilis (Linnaeus, 1758) ( $n=8)-\quad$ MNR): 930, 2670, 2671, 2681, 4923, 4936, 34504, nc = 13635.

Sphiggurus villosus (F. Cuvier, 1823) ( $\mathrm{n}=2)$ - ZUEC: 1508, 1636.

Muridae

Akodon cursor (Winge, 1887) $(\mathrm{n}=13)$ - MNR): 4368, 4372, 7546, 11690, 19127, 19139, 28843, 30598, $30607,32836,32841$. UFPR: 745, 785.

Bolomys lasiurus (Lund, 1841) ( $\mathrm{n}=12$ ) - MNR): 4375, 7461, 8498, 13007, 21687, 24185, 43756, 44203, 44600, 47496. ZUEC: 1402, 1403.

Delomys dorsalis (Hensel, 1872) $(n=4)$ - espécimes não coletados capturados em um estudo de dinâmica populacional em Mananciais da Serra, Piraquara, PR.

Holochilus brasiliensis (Desmarest, 1819) ( $\mathrm{n}=13)$ - MNRJ: 1988, 2077, 4208, 7765, 8339, 17466, 20630, 21266, 34181, NC/ CA2309, NC/8544. ZUEC: 1233, 1512.

Nectomys squamipes (Brants, 1827) ( $\mathrm{n}=15)$ - MNRJ: 2079, 4371, 4474, 5414, 8290, 12443, 13425, 21330, 30579, 33811, 42686, 50180. UFSC: 2958. ZUEC: 1258, 1262.

Oecomys trinitatis (J. A. Allen and Chapman, 1893) ( $n=1)$ - UFSC: 905.

Oligoryzomys nigripes (Olfers, 1818) $(\mathrm{n}=1)$ - UFSC: 48.

Oryzomys intermedius (Leche, 1886) ( $\mathrm{n}=2)$ - UFSC: 921, 2997.

Oryzomys ratticeps (Hensel, 1873) $(\mathrm{n}=2)-\mathrm{MNRJ}$ : 44815. UFSC: 283.

Oxymycterus hispidus Pictet, $1843(\mathrm{n}=2)$ - MNRJ: NC/LF757. ZUEC: 1270.

Oxymycterus iheringi Thomas, $1896(n=1)-$ MNRJ: NC/LF2168.

Lagomorpha

Leporidae

Lepus europaeus Pallas, 1778 ( $\mathrm{n}=5$ ) - MHNCI: 2725, 3406, 3408, 3740, 3745.

Sylvilagus brasiliensis (Linnaeus, 1758) $(\mathrm{n}=14)-\quad \mathrm{MHNCl}: 2426,3398,3420,3736$. MNRJ: 1837, 4109, 4768, 24037, 24039, 24048, 24071, 34441. ZUEC: 1423, 1786. 